\title{
The content of hydrogen sulfide in plasma of cirrhosis rats combined with portal hypertension and the correlation with indexes of liver function and liver fibrosis
}

\author{
WEIWEI WEI, CHAO WANG and DONGJIAN LI \\ Department of General Surgery, Tongji Hospital, Tongji Medical College, \\ Huazhong University of Science and Technology, Wuhan, Hubei 430030, P.R. China
}

Received June 21, 2017; Accepted September 12, 2017

DOI: $10.3892 /$ etm.2017.5133

\begin{abstract}
The purpose of this study is to investigate the content of hydrogen sulfide $\left(\mathrm{H}_{2} \mathrm{~S}\right)$ in plasma of cirrhosis rats combined with portal hypertension and the correlation with indexes of liver function and liver fibrosis. Thirty female Sprague-Dawley rats were randomly divided into normal control group (NC), liver cirrhosis group (LC) and cirrhosis + propargylglycine $(\mathrm{PPG})$ group ( $\mathrm{LC}+\mathrm{PPG})$. Cirrhosis and portal hypertension were induced by carbon tetrachloride. Rats in LC+PPG group were intraperitoneally injected with $\mathrm{H}_{2} \mathrm{~S}$ synthase inhibitor PPG for one week. Portal vein catheterization was used to measure portal vein pressure (PVP), and plasma $\mathrm{H}_{2} \mathrm{~S}$ content was determined by deproteinization. Liver function was measured by automatic biochemical analyzer, and the fibrosis index was determined by radioimmunoassay. Real-time PCR was used to detect the expression levels of type I and type III collagen mRNA in liver tissue. Compared with $\mathrm{NC}$ group, levels of plasma $\mathrm{H}_{2} \mathrm{~S}$ were significantly decreased $(\mathrm{P}<0.01)$, while $\mathrm{PVP}$, alanine aminotransferase (ALT), aspartate aminotransferase (AST), laminin (LN), hyaluronic acid (HA), and expression levels of type III procollagen (PC III) and type I and type III collagen mRNAs were significantly increased in LC and LC+PPG groups $(\mathrm{P}<0.01)$. Compared with LC group, levels of plasma $\mathrm{H}_{2} \mathrm{~S}$ were significantly decreased $(\mathrm{P}<0.01)$, while PVP, ALT, AST, LN, HA, and expression levels of PC III and type I and type III collagen mRNAs in $\mathrm{LC}+\mathrm{PPG}$ group $(\mathrm{P}<0.05$ or $\mathrm{P}<0.01$ ). In conclusion, level of $\mathrm{H}_{2} \mathrm{~S}$ was decreased and PVP was increased in cirrhosis rats, and $\mathrm{H}_{2} \mathrm{~S}$ has the function of protecting liver function and anti-fibrosis.
\end{abstract}

Correspondence to: Dr Dongjian Li, Department of General Surgery, Tongji Hospital, Tongji Medical College, Huazhong University of Science and Technology, 1095 Jiefang Street, Wuhan, Hubei 430030, P.R. China

E-mail: 1be67x@163.com; lidongjian@vip.sina.com

Key words: cirrhosis, portal hypertension, hydrogen sulfide, liver function, liver fibrosis

\section{Introduction}

Liver cirrhosis is the manifestation of end-stage chronic liver diseases caused by viral infection, immune disorder and drug related factors and other factors (1). Histological manifestations of liver cirrhosis include the diffused hepatocellular degeneration and necrosis, and the followed hepatocellular nodular regeneration and fibrous tissue hyperplasia. During the development of liver cirrhosis, liver cell degeneration and necrosis, nodular regeneration and fibrous tissue hyperplasia occur, which in turn lead to liver deformation and hardening, resulting in cirrhosis (1). Clinical manifestations usually cannot be observed in patients with early stage of liver cirrhosis, while liver dysfunction and portal hypertension can usually be observed in later stage (2). Liver fibrosis is the key stage of a variety of chronic hepatitis to progress to liver cirrhosis. Studies have shown that $(3,4)$, early detection and treatment of liver fibrosis can effectively control or even reverse the progression of this disease, thereby preventing the progression to cirrhosis. Carbon monoxide (CO) and nitric oxide (NO) and other endogenous gas signal molecules, which can effectively maintain the portal vein relaxation, are important mediators in expanding vessels and have important functions in maintaining the diastolic state of sinus hepaticus (5). Endogenous hydrogen sulfide $\left(\mathrm{H}_{2} \mathrm{~S}\right)$ is a newly discovered endogenous gas signal molecule, and the synthesis of $\mathrm{H}_{2} \mathrm{~S}$ is regulated by a number of metabolic pathways in vivo (6). $\mathrm{H}_{2} \mathrm{~S}$ is mainly synthesized by cystathionine- $\beta$-synthetase and cystathionine- $\gamma$-lyase using 1-cysteine (7). $\mathrm{H}_{2} \mathrm{~S}$ has similar pathophysiological functions to those of $\mathrm{NO}$ and $\mathrm{CO}(8) . \mathrm{H}_{2} \mathrm{~S}$ can reduce liver cell damage in a variety of ways in the development of liver disease $(9,10)$. In this study, cirrhosis with portal hypertension rat model was established and the model rats were treated by propargylglycine (PPG), which is an inhibitor of cystathionine- $\gamma$-lyase. Changes of $\mathrm{H}_{2} \mathrm{~S}$ content in portal veins, portal vein pressure (PVP) and indexes of liver function and fibrosis were observed to investigate the changes of $\mathrm{H}_{2} \mathrm{~S}$ content in development portal hypertension and its correlation with indexes of liver function and fibrosis, so as to provide the basis for clinical diagnosis and treatment. 


\section{Materials and methods}

Experimental reagents. PPG (Sigma, San Francisco, CA, USA); carbon tetrachloride, zinc acetate, trichloroacetic acid and p-amino-dimethyianiline dihydrochloride (Sinapharm Chemical Reagent Co., Ltd.); laminin (LN), hyaluronic acid (HA), type III procollagen (PCIII) detection kits (Naval Medical Research Institute, Shanghai, China); TRIzol (Takara, Shiga, Japan); reverse transcription kit (Toyobo, Osaka, Japan); primers for type I, type III collagen and glyceraldehyde-3phosphate dehydrogenase (GAPDH) (Sangon, Shanghai, China); SYBR-Green PCR Master Mix (Takara).

Experimental instruments. Automatic biochemical analyzer (Mindray, Shenzhen, China); 12 channels physiological record instrument (Biopac Systems, Inc., Goleta, CA, USA); ultramicroscale ultraviolet spectrophotometer (Thermo Fisher Scientific, Inc., Waltham, MA, USA); continuous wavelength multifunctional microplate reader (Tecan Austria GmbH, Grödig, Austria); real-time PCR instrument (Eppendorf, Hamburg, Germany).

Model establishment and grouping. Thirty SPF grade female Sprague-Dawley rats (4-5 weeks, 180-200 g) were purchased from Shanghai SLAC Laboratory Animal Co., Ltd., (Shanghai, China) license no: SCXK (Shanghai) 2012-0002. Rats were randomly divided into 3 groups including normal control group (NC), liver cirrhosis group (LC) and cirrhosis + PPG group ( $\mathrm{LC}+\mathrm{PPG})$ with 10 rats in each group. All rats were raised in SPF environment with free access to food and water. Cirrhosis and portal hypertension model was established by carbon tetrachloride induction. Rats in LC and LC+PPG groups were injected subcutaneously with $40 \%$ carbon tetrachloride (diluted with cotton seed oil) at a dose of $0.5 \mathrm{ml} / 0.1 \mathrm{~kg}$ for the first time and $0.3 \mathrm{ml} / 0.1 \mathrm{~kg}$ for the rest. Injection was performed every four days, and a total of 13 injections were performed. At the same time, rats in LC and LC+PPG groups were treated with $15 \%$ ethanol solution as drinking water and fed with high fat and high cholesterol diet. Rats in NC group were injected subcutaneously with the same dose of cottonseed oil, and fed with normal food and water. After model establishment, rats in $\mathrm{LC}+\mathrm{PPG}$ rats were injected intraperitoneally with PPG at a dose of $30 \mathrm{mg} / \mathrm{kg}$, once per day, while rats in NC and LC groups were injected intraperitoneally with normal saline, and injection was performed for 7 days. The study was approved by the Ethics Committee of Tongji Hospital.

Measurement of PVP. PVP was measured using portal vein catheterization. Rats were injected intraperitoneally with $10 \%$ chloral hydrate for anesthesia. An incision was made in the middle of the abdomen to expose the visceral tissue. Small intestine was separated and dragged to bottom left to expose the trunk of portal vein. A number 5.5 scalp needle was fixed in the trunk of portal vein, and the other end was connected to 12 channels physiological record instrument to measure PVP. PVP $>12 \mathrm{mmHg}$ was used as a standard for formation of portal hypertension.

Measurement of $\mathrm{H}_{2} \mathrm{~S}$ content in plasma of portal vein. A $1 \mathrm{ml}$ syringe was used to extract blood from portal vein. Blood was
Table I. Primer sequences.

\begin{tabular}{ll} 
Gene & \multicolumn{2}{c}{ Sequences } \\
\hline Type I collagen & F: 5'-GGCTTCTTCAAACCACTGCTTT-3' \\
& R: 5'-AAAGTCATAGCCACCTCCGCTG-3' \\
Type III collagen & F: 5'-CTCCCAGAACATTACATAC-3' \\
& R: 5'-AATGTCATAGGGTGCGATA-3' \\
GAPDH & F: 5'-AGGTCGGTGTGAACGGATTTG-3' \\
& R: 5'-GGGGTCGTTGATGGCAACA-3'
\end{tabular}

F, forward; R, reverse.

transferred to an anticoagulant tube, followed by centrifugation to separate plasma. Plasma $\mathrm{H}_{2} \mathrm{~S}$ content was determined by deproteinization (11). Plasma $(0.1 \mathrm{ml})$ was mixed with $0.5 \mathrm{ml}$ of $10 \mathrm{~g} / \mathrm{l}$ zinc acetate by vortex oscillation. Then $0.5 \mathrm{ml}$ of $20 \mathrm{mmol} / \mathrm{l} \mathrm{p}$-aminodimethylaniline hydrochloride and $0.5 \mathrm{ml}$ of $30 \mathrm{mmol} / \mathrm{l}$ trichloroacetic acid were added. Finally, distilled water was added to make a total volume of $5 \mathrm{ml}$. After vortex oscillation, the mixture was centrifuged at $(5,200 \mathrm{x} \mathrm{g}$, $4^{\circ} \mathrm{C}$ ) for $5 \mathrm{~min}$ to separate the supernatant. OD values were measured at $670 \mathrm{~nm}$ using a continuous wavelength multifunctional microplate reader. A standard curve was drawn and $\mathrm{H}_{2} \mathrm{~S}$ content was calculated.

Determination of liver function and fibrosis indexes. Blood was extracted from abdominal aorta to prepare serum samples. Levels of alanine aminotransferase (ALT) and aspartate aminotransferase (AST) were determined by automatic biochemical analyzer. Liver fibrosis indexes LN, HA and PC III were determined using radioimmunoassay in strict accordance with the kit instructions.

RNA extraction from liver tissue and reverse transcription. Liver tissue was collected from the left lobe, and total RNA was extracted using TRIzol according to the instructions. Concentration and purity of RNA were determined by UV spectrophotometer. Only RNA samples of satisfactory concentration and purity were used for reverse transcription. Total RNA $(2 \mu \mathrm{g})$ was denatured at $65^{\circ} \mathrm{C}$ for $5 \mathrm{~min}$, and was immediately placed on ice, and $4 \mu \mathrm{l} 5 \mathrm{X}$ RT Master Mix was then added, and DEPC treated water was also added to make a total volume of $20 \mu \mathrm{l}$. Reaction conditions were $37^{\circ} \mathrm{C}$ for $15 \mathrm{~min}$, $52^{\circ} \mathrm{C}$ for $5 \mathrm{~min}$ and $98^{\circ} \mathrm{C}$ for $5 \mathrm{~min}$.

qRT-PCR to determine the expression of type I and type III collagen $m R N A$ s in liver tissue. Primers for Type I collagen, type III collagen and GAPDH were listed in Table I. Reaction system was: $2 \mu \mathrm{l}$ of cDNA, $0.5 \mu \mathrm{l}$ of each primer, $12.5 \mu \mathrm{l}$ of $2 \mathrm{X}$ SYBR Green PCR Master Mix and $9.5 \mu \mathrm{l}$ of ultra-pure water. PCR reaction was performed on a realtime PCR instrument. Reaction conditions were $95^{\circ} \mathrm{C}$ for $30 \mathrm{sec}$, followed by 40 cycles of $95^{\circ} \mathrm{C}$ for $5 \mathrm{sec}$ and $60^{\circ} \mathrm{C}$ for $30 \mathrm{sec}$. $\mathrm{Ct}$ values were processed using $2-\Delta \Delta \mathrm{Ct}$ to calculate the relative expression level of each gene with GAPDH as endogenous control. 


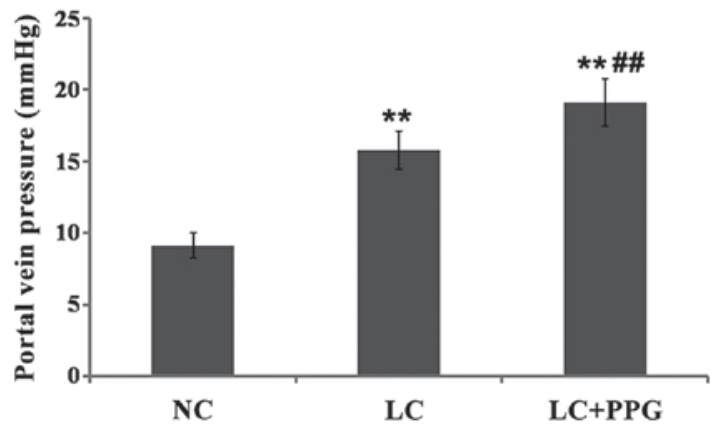

Figure 1. PVP of rats in each group. Results showed that PVP was significantly increased in LC and LC+PPG groups compared with NC group $(\mathrm{P}<0.01)$, and $\mathrm{PVP}$ of $\mathrm{LC}+\mathrm{PPG}$ group was significantly increased compared with LC group $(\mathrm{P}<0.01) .{ }^{* * *} \mathrm{P}<0.01$ compared with the $\mathrm{NC}$ group; ${ }^{\# \prime} \mathrm{P}<0.01$ compared with the LC group.

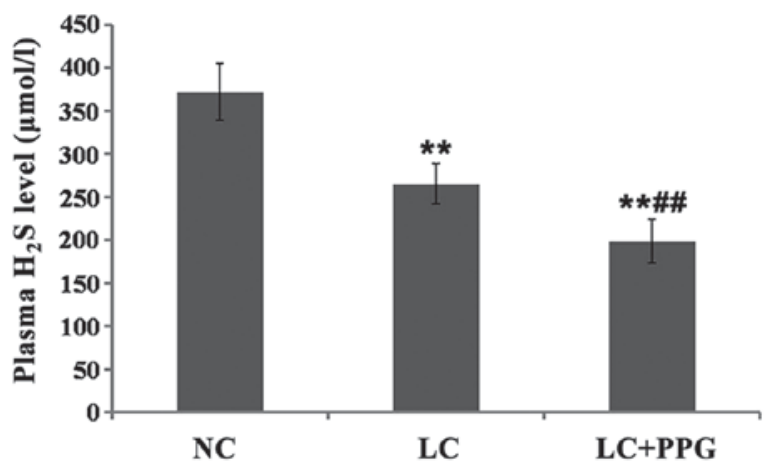

Figure 2. Plasma $\mathrm{H}_{2} \mathrm{~S}$ levels in three groups of rats determined by deproteinization. Results showed that $\mathrm{H}_{2} \mathrm{~S}$ level in $\mathrm{LC}$ and $\mathrm{PP}+\mathrm{PPG}$ rats was significantly lower than that in $\mathrm{NC}$ group $(\mathrm{P}<0.01)$, and $\mathrm{H}_{2} \mathrm{~S}$ level in $\mathrm{LC}+\mathrm{PPG}$ group was significantly lower than that in $\mathrm{LC}$ group $(\mathrm{P}<0.01)$. ${ }^{* *} \mathrm{P}<0.01 \mathrm{com}-$ pared with the $\mathrm{NC}$ group; ${ }^{\# \#} \mathrm{P}<0.01$ compared with the LC group.

Statistical analysis. Experimental results were expressed as mean \pm standard deviation and SPSS 20.0 statistical software (IBM, Armonk, NY, USA) was used for statistical analysis. Comparisons between two groups were performed by independent sample t-test, and comparisons among multiple groups were performed by single factor analysis of variance. $\mathrm{P}<0.05$ was considered to indicate a statistically significant difference.

\section{Results}

Changes in PVP. PVP of rats in LC and LC+PPG were all $>12 \mathrm{mmHg}$, indicating the successfully established cirrhosis and portal hypertension model. Compared with NC group, PVP was significantly increased in LC and LC+PPG groups $(\mathrm{P}<0.01)$. The $\mathrm{PVP}$ of $\mathrm{LC}+\mathrm{PPG}$ group was significantly higher than that of LC group $(\mathrm{P}<0.01)$ (Fig. 1).

Changes in plasma $\mathrm{H}_{2} \mathrm{~S}$ levels. Compared with NC group, plasma $\mathrm{H}_{2} \mathrm{~S}$ level was significantly decreased in LC and $\mathrm{LC}+\mathrm{PPG}$ groups $(\mathrm{P}<0.01)$. Plasma $\mathrm{H}_{2} \mathrm{~S}$ level in $\mathrm{LC}+\mathrm{PPG}$ group was significantly lower than that in LC group $(\mathrm{P}<0.01)$ (Fig. 2).

Comparison of liver function between groups. Compared with NC group, levels of ALT and AST in LC and LC+PPG groups were significantly increased $(\mathrm{P}<0.01)$. Levels of ALT and AST

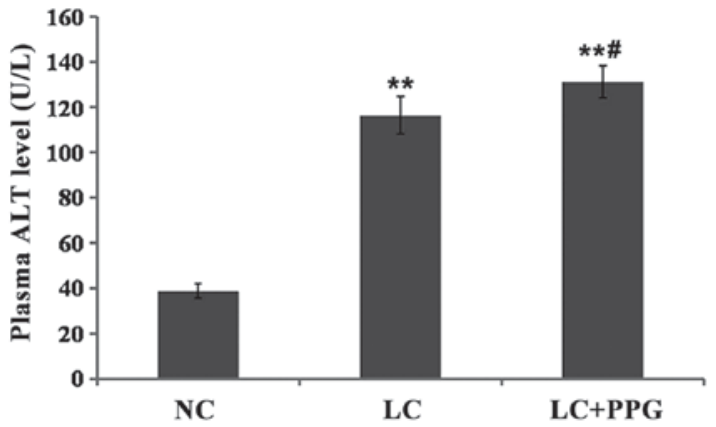

Figure 3. Serum ALT level in each group of rats detected by automatic biochemical analyzer. Results showed that serum ALT level in LC and PP+PPG rats were significantly higher than that in $\mathrm{NC}$ group $(\mathrm{P}<0.01)$, and serum ALT level in LC+PPG group was significantly higher than that of LC group $(\mathrm{P}<0.05) .{ }^{* *} \mathrm{P}<0.01$ compared with the $\mathrm{NC}$ group; ${ }^{\#} \mathrm{P}<0.05$ compared with the LC group.

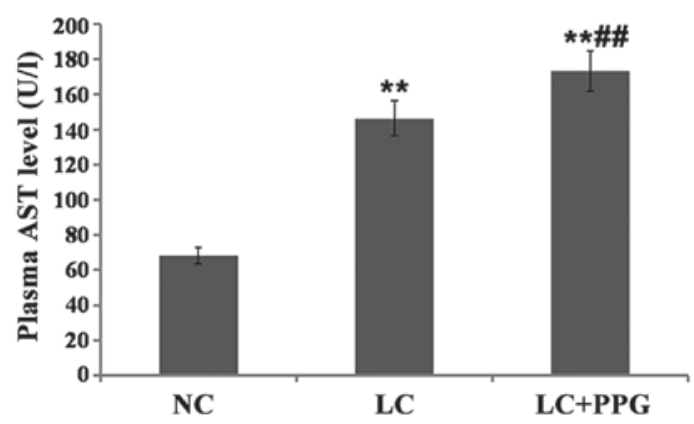

Figure 4. Serum AST level in each group of rats detected by automatic biochemical analyzer. Results showed that serum AST level in LC and PP+PPG rats were significantly higher than that in $\mathrm{NC}$ group $(\mathrm{P}<0.01)$, and serum AST level in LC+PPG group was significantly higher than that of LC group $(\mathrm{P}<0.05) .{ }^{* *} \mathrm{P}<0.01$ compared with $\mathrm{NC}$ group; ${ }^{\#} \mathrm{P}<0.01$ compared with the LC group.

Table II. Comparison of fibrosis indexes among groups.

\begin{tabular}{lcccc}
\hline Groups & Cases & LN $(\mu \mathrm{g} / 1)$ & HA $(\mu \mathrm{g} / 1)$ & PC III $(\mu \mathrm{g} / 1)$ \\
\hline NC & 10 & $46.25 \pm 6.43$ & $125.09 \pm 12.84$ & $68.16 \pm 9.57$ \\
LC & 10 & $80.68 \pm 7.70^{\mathrm{a}}$ & $276.36 \pm 14.63^{\mathrm{a}}$ & $183.48 \pm 15.92^{\mathrm{a}}$ \\
LC+PPG & 10 & $91.51 \pm 9.36^{\mathrm{a}, \mathrm{b}}$ & $313.3 \pm 13.09^{\mathrm{a}, \mathrm{c}}$ & $227 . \pm 17.03^{\mathrm{a}, \mathrm{c}}$ \\
\hline
\end{tabular}

${ }^{\mathrm{a}} \mathrm{P}<0.01$ compared with $\mathrm{NC}$ group; ${ }^{\mathrm{b}} \mathrm{P}<0.05$ compared with $\mathrm{LC}$ group; ${ }^{\mathrm{C}} \mathrm{P}<0.01$ compared with LC group.

in LC+PPG group were significantly higher than those in LC group $(\mathrm{P}<0.05$ or $\mathrm{P}<0.01)$ (Figs. 3 and 4$)$.

Comparison of fibrosis indexes among groups. Compared with NC group, levels of serum LN, HA and PC III in LC and $\mathrm{LC}+\mathrm{PPG}$ groups were significantly increased $(\mathrm{P}<0.01)$. Levels of serum LN, HA and PC III in LC+PPG group were significantly higher than those in $\mathrm{LC}$ group $(\mathrm{P}<0.01$ or $\mathrm{P}<0.05$ ) (Table II).

Comparison of expression levels of type I and type III collagen mRNAs among groups. Compared with NC group, 
Table III. Comparison of expression levels of type I and type III collagen mRNAs among groups.

\begin{tabular}{lccc}
\hline Groups & Cases & Type I collagen & Type III collagen \\
\hline NC & 10 & $1.02 \pm 0.13$ & $1.03 \pm 0.11$ \\
LC & 10 & $2.14 \pm 0.32^{\mathrm{a}}$ & $1.88 \pm 0.41^{\mathrm{a}}$ \\
LC+PPG & 10 & $3.01 \pm 0.47^{\mathrm{a}, \mathrm{c}}$ & $2.49 \pm 0.52^{\mathrm{a}, \mathrm{b}}$ \\
\hline
\end{tabular}

${ }^{\mathrm{a}} \mathrm{P}<0.01$ compared with $\mathrm{NC}$ group; ${ }^{\mathrm{b}} \mathrm{P}<0.05$ compared with $\mathrm{LC}$ group; ${ }^{\mathrm{c}} \mathrm{P}<0.01$ compared with $\mathrm{LC}$ group.

expression levels of type I and type III collagen mRNA in LC and $\mathrm{LC}+\mathrm{PPG}$ groups were significantly increased $(\mathrm{P}<0.01)$. In addition, expression levels of type I and type III collagen mRNA LC+PPG group were significantly higher than those in LC group $(\mathrm{P}<0.05$ or $\mathrm{P}<0.01)$ (Table III).

\section{Discussion}

Endogenous $\mathrm{H}_{2} \mathrm{~S}$, as a new type of gas signaling molecule discovered after $\mathrm{CO}$ and $\mathrm{NO}$, has been proved with the functions of dilating blood vessels (12), protecting the myocardium (13) and anti-inflammatory $(14,15)$. Endogenous $\mathrm{H}_{2} \mathrm{~S}$ is present in two forms including gases or sodium hydrosulfide. Studies have shown that gas forms account for about one-third, while sodium hydrosulfide forms account for two-thirds. The dynamic balance between those forms maintains the $\mathrm{pH}$ level of internal environment of the body (16). $\mathrm{H}_{2} \mathrm{~S}$ is mainly synthesized in the liver, and liver plays an important role in maintaining blood concentration of $\mathrm{H}_{2} \mathrm{~S}$, while $\mathrm{H}_{2} \mathrm{~S}$ can regulate the microcirculation of the liver (17).

Cirrhosis is a liver disease caused by various factors with portal hypertension and liver dysfunctions as the main manifestations. The pathological features of cirrhosis include increased extracellular matrix and hepatic stellate cell activation, and cirrhosis is usually combined with liver cell degeneration and necrosis, nodular regeneration and fibrous tissue hyperplasia (1). The key step of the occurrence of liver cirrhosis is in hepatic stellate cells. Activated hepatic stellate cells have similar characteristics of vascular smooth muscle cells, which can regulate blood flow of sinus hepaticus and intrahepatic resistance (18). Studies have showed that the activity of cystathionine- $\gamma$-lyase in hepatic stellate cells of cirrhosis animal model was significantly reduced, resulting in a significant reduction in $\mathrm{H}_{2} \mathrm{~S}$ production, and then cause contraction of hepatic stellate cells in sinus hepaticus, thereby increasing the portal hypertension $(17,19)$. Another study found that $\mathrm{H}_{2} \mathrm{~S}$ can regulate the portal vein pressure by modulating hepatic artery buffer system and dilating hepatic arteries (20). In addition, $\mathrm{H}_{2} \mathrm{~S}$ may affect the formation of portal hypertension by participating in the opening of the $\mathrm{K}^{+}$-ATP channel (21). In vascular smooth muscle cells of portal vein, $\mathrm{H}_{2} \mathrm{~S}$ can activate $\mathrm{K}^{+}$-ATP channel to cause hyperpolarization of cell membrane, thereby reducing the concentration of free calcium ions in vascular smooth muscle cells, and ultimately lead to the relaxation and expansion of vascular smooth muscle. This study found that the plasma $\mathrm{H}_{2} \mathrm{~S}$ content was significantly reduced in rats with cirrhosis and portal hypertension, and $\mathrm{H}_{2} \mathrm{~S}$ content was further reduced ad PVP was further increased after the treatment of PPG, indicating that $\mathrm{H}_{2} \mathrm{~S}$ can inhibit the formation of portal hypertension. Higher portal hypertension is followed by the lower plasma $\mathrm{H}_{2} \mathrm{~S}$ content.

Hepatic fibrosis is the key step of a variety of chronic hepatitis to progress to cirrhosis. The pathogenesis of liver fibrosis is very complex. Liver damage caused by virus, drug and other factor can stimulate macrophages to release inflammatory cytokines, these cytokines can participate in the production and degradation of extracellular collagen, and the activation and apoptosis of hepatic stellate cell through a variety of ways (22), which eventually leads to fibrosis. It has been found that $\mathrm{H}_{2} \mathrm{~S}$ can promote apoptosis of vascular smooth muscle cells by downregulating the level of apoptosis inhibitors such as Bcl-2 and NF- $\mathrm{kB}$ (23). Another study found that $\mathrm{H}_{2} \mathrm{~S}$ can inhibit the expression of type I and III procollagen mRNA in the muscular arteries of the lungs, thereby reducing the levels of collagen type I and type III proteins (24). This study found that ALT and AST were significantly increased, expression level of fibrosis indexes LN, HA and PC III and type I and type III collagen were also significantly increased in cirrhosis rats combined with portal hypertension. The levels of those factors were further increased after PPG treatment. Therefore, $\mathrm{H}_{2} \mathrm{~S}$ content is negatively correlated with the levels of liver function and fibrosis indexes, suggesting that $\mathrm{H}_{2} \mathrm{~S}$ can protect liver function and inhibit fibrosis in portal hypertension.

In conclusion, in carbon tetrachloride-induced cirrhosis and portal hypertension rat model, plasma $\mathrm{H}_{2} \mathrm{~S}$ level was inversely proportional to PVP, and $\mathrm{H}_{2} \mathrm{~S}$ can reduce portal hypertension, protect liver function and inhibit fibrosis, thus delaying the progress of liver cirrhosis. Further studies are still needed to investigate the possible synergistic or antagonistic interactions of $\mathrm{H}_{2} \mathrm{~S}$ with $\mathrm{NO}, \mathrm{CO}$ and other signal molecules in the development of cirrhosis.

\section{Acknowledgements}

The present study was supported by the Natural Science Foundation of China, no. 30901430.

\section{References}

1. Friedman SL: Molecular regulation of hepatic fibrosis, an integrated cellular response to tissue injury. J Biol Chem 275: 2247-2250, 2000.

2. Bonis PA, Friedman SL and Kaplan MM: Is liver fibrosis reversible? N Engl J Med 344: 452-454, 2001.

3. Loguercio $\mathrm{C}$ and Federico A: Oxidative stress in viral and alcoholic hepatitis. Free Radic Biol Med 34: 1-10, 2003.

4. Kitade Y, Watanabe S, Masaki T, Nishioka M and Nishino H: Inhibition of liver fibrosis in LEC rats by a carotenoid, lycopene, or a herbal medicine, Sho-saiko-to. Hepatol Res 22: 196-205, 2002.

5. La Villa G and Gentilini P: Hemodynamic alterations in liver cirrhosis. Mol Aspects Med 29: 112-118, 2008.

6. Geng B, Yang J, Qi Y, Zhao J, Pang Y, Du J and Tang C: $\mathrm{H}_{2} \mathrm{~S}$ generated by heart in rat and its effects on cardiac function. Biochem Biophys Res Commun 313: 362-368, 2004.

7. Calvert JW, Coetzee WA and Lefer DJ: Novel insights into hydrogen sulfide - mediated cytoprotection. Antioxid Redox Signal 12: 1203-1217, 2010.

8. Hosoki R, Matsuki N and Kimura H: The possible role of hydrogen sulfide as an endogenous smooth muscle relaxant in synergy with nitric oxide. Biochem Biophys Res Commun 237: 527-531, 1997. 
9. Kang K, Zhao M, Jiang H, Tan G, Pan S and Sun X: Role of hydrogen sulfide in hepatic ischemia-reperfusion-induced injury in rats. Liver Transpl 15: 1306-1314, 2009.

10. Tan G, Pan S, Li J, Dong X, Kang K, Zhao M, Jiang X, Kanwar JR, Qiao H, Jiang H, et al: Hydrogen sulfide attenuates carbon tetrachloride-induced hepatotoxicity, liver cirrhosis and portal hypertension in rats. PLoS One 6: e25943, 2011.

11. Ali MY, Ping CY, Mok YY, Ling L, Whiteman M, Bhatia M and Moore PK: Regulation of vascular nitric oxide in vitro and in vivo; a new role for endogenous hydrogen sulphide? $\mathrm{Br} \mathrm{J}$ Pharmacol 149: 625-634, 2006.

12. Mel Nik AV, Voloshchouk NI, Pentyuk NO and Zaichko KO Role of hydrogen sulfide and sulfur-containing amino acids in regulation of tone of smooth muscles of the vascular wall in rats Neurophysiology 42: 126-131, 2010.

13. Chuah SC, Moore PK and Zhu YZ: S-allylcysteine mediates cardioprotection in an acute myocardial infarction rat model via a hydrogen sulfide-mediated pathway. Am J Physiol Heart Circ Physiol 293: H2693-H2701, 2007.

14. Sidhapuriwala JN, Ng SW and Bhatia M: Effects of hydrogen sulfide on inflammation in caerulein-induced acute pancreatitis. J Inflamm (Lond) 6: 35, 2009.

15. Hirata I, Naito Y, Takagi T, Mizushima K, Suzuki T, Omatsu T, Handa O, Ichikawa H, Ueda $\mathrm{H}$ and Yoshikawa T: Endogenous hydrogen sulfide is an anti-inflammatory molecule in dextran sodium sulfate-induced colitis in mice. Dig Dis Sci 56: 1379-1386, 2011.

16. Chunyu Z, Junbao D, Dingfang B, Hui Y, Xiuying $T$ and Chaoshu T: The regulatory effect of hydrogen sulfide on hypoxic pulmonary hypertension in rats. Biochem Biophys Res Commun 302: 810-816, 2003

17. Fiorucci S, Antonelli E, Mencarelli A, Orlandi S, Renga B, Rizzo G, Distrutti E, Shah V and Morelli A: The third gas: $\mathrm{H}_{2} \mathrm{~S}$ regulates perfusion pressure in both the isolated and perfused normal rat liver and in cirrhosis. Hepatology 42: 539-548, 2005.
18. Bauer M, Bauer I, Sonin NV, Kresge N, Baveja R, Yokoyama Y, Harding D, Zhang JX and Clemens MG: Functional significance of endothelin B receptors in mediating sinusoidal and extrasinusoidal effects of endothelins in the intact rat liver. Hepatology 31: 937-947, 2000.

19. Bosy-Westphal A, Petersen S, Hinrichsen H, Czech N and J Müller M: Increased plasma homocysteine in liver cirrhosis. Hepatol Res 20: 28-38, 2001

20. Siebert N, Cantré D, Eipel C and Vollmar B: $\mathrm{H}_{2} \mathrm{~S}$ contributes to the hepatic arterial buffer response and mediates vasorelaxation of the hepatic artery via activation of K(ATP) channels. Am J Physiol Gastrointest Liver Physiol 295: G1266-G1273, 2008.

21. Dawe GS, Han SP, Bian JS and Moore PK: Hydrogen sulphide in the hypothalamus causes an ATP-sensitive $\mathrm{K}^{+}$channeldependent decrease in blood pressure in freely moving rats. Neuroscience 152: 169-177, 2008.

22. Jeong EJ, Kim NH, Heo JD, Lee KY, Rho JR, Kim YC and Sung SH: Antifibrotic compounds from Liriodendron tulipifera attenuating HSC-T6 proliferation and TNF- $\alpha$ production in RAW264.7 cells. Biol Pharm Bull 38: 228-234, 2015.

23. Liu YF, Chu YY, Zhang XZ, Zhang M, Xie FG, Zhou M, Wen HH and Shu AH: TGF $\beta 1$ protects myocardium from apoptosis and oxidative damage after ischemia reperfusion. Eur Rev Med Pharmacol Sci 21: 1551-1558, 2017.

24. Wang YX, Liu ML, Zhang B, Fu EQ and Li ZC: Fasudil alleviated hypoxia-induced pulmonary hypertension by stabilizing the expression of angiotensin-(1-7) in rats. Eur Rev Med Pharmacol Sci 20: 3304-3312, 2016. 